\title{
Determining Individual Workload Perceptions and Malpractice Tendencies Among Operating Room Nurses
}

\author{
Aysegul Savci ${ }^{1}$ (D), Kevser Karacabay ${ }^{1}$ (D), Saadet Comez $^{2}$ (D), Selda Karaveli ${ }^{3}$ (D), Nigar Celik ${ }^{1}$ (D) \\ ${ }^{1}$ Kutahya University of Health Science, Faculty of Health Science, Department of Nursing, Kutahya, Turkey. \\ ${ }^{2}$ Mehmet Akif Ersoy University, Faculty of Health Science, Department of Nursing, Burdur, Turkey. \\ ${ }^{3}$ Kastamonu University, Fazil Boyner Faculty of Health Science, Department of Nursing, Kastamonu, Turkey.
}

Correspondence Author: Aysegul Savci

E-mail: aysegul.savci@ksbu.edu.tr

Received: $02.10 .2019 \quad$ Accepted: 20.09 .2020

\begin{abstract}
Objective: To determine the workload perceptions and malpractice tendency of nurses working in the operating room.

Methods: A descriptive, cross-sectional study was conducted with 92 operating room nurses from 3 provinces of Turkey. The data were analyzed by using the numbers, percentages, the Mann-Whitney $U$ test and the Kruskal Wallis test.

Results: The mean age of the nurses was $35.19 \pm 6.11 ; 50 \%$ of the nurses had operating room working duration of $1-5$ years, and $78.3 \%$ of the nurses had weekly working hours more than 40 hours. A total of $33.7 \%$ of the nurses stated that they came across with one malpractice case. The mean "Individual Workload Perception Scale(IWPS)" score of the participants was $98.82 \pm 9.39$, and the mean "Malpractice Tendency Scale(MTS)" score was $225.59 \pm 12.75$. There was a statistically significant difference between the communication subscale mean scores of the participants on the MTS according to their time in the profession. There were statistically significant differences between the gender of the participants and the overall IWPS mean score, the managerial support subscale mean score, and the workload subscale score. Statistically significant differences were detected between the working time of the nurses and the managerial support subscale and the workload subscale scores. Significant differences were detected in the participants' mean scores on the intention to stay at work subscale of the IWPS according to the operating room working time of the participants.

Conclusion: Teamwork and effective communication in the operating room are two critical factors in ensuring patient safety. Eventually, approaches to be developed to foresee and prevent malpractice in operating rooms may ensure a safe perioperative process. The job descriptions of the operating room nurses should be reviewed. Training should be planned to strengthen team communication. Patient safety culture should be expanded in the health care team through monitoring and work flow charts.
\end{abstract}

Keywords: Operating Room, Nurse, Malpractice, Workload.

\section{INTRODUCTION}

Operating rooms are high-risk areas for malpractice due to factors such as their complex structure, the intensive working environment and having to function with insufficient personnel, a high workload, and stress (1-3). In the United States, it was determined that $12.5 \%$ of the 1100 malpractice cases in the courts between 1995 and 2001 were brought during or after operations (4). Malpractice in operating rooms include wrong side surgery, forgetting a foreign body, transfusion errors, falls, hospital infections, medication errors, surgical burns, faulty anesthesia, and sharp object injuries $(5,6)$. Malpractice in an operating room causes serious injury, organ loss, prolonged hospital stay, and can even result in mortality $(7,8)$. Reasons for malpractice in operating rooms include urgency of the intervention, unusual physical characteristics of the patient, inadequate patient consent, time pressure, working with multiple surgeons, and simultaneous interventions to the same patient. Moreover, poor communication, the inexperience of healthcare workers, distraction, the importance personnel attribute to their jobs, their physical and/or psychological problems, and the physical environment (many risky devices, multiple complicated procedures) are also important causes of malpractice. Stress, an intensive work schedule, insufficient rest, lack of managerial support, not feeling safe, confusion in job descriptions, high expectations, organizational problems, fatigue, long hours or shift work, and sleeplessness are also important factors (9). In addition to these, a shortage of nurses leads to an increase in individual workloads. Under such conditions, malpractice, which is in fact preventable, becomes unavoidable $(5,8,10)$. To understand the causes of malpractice and to prevent performance that leads to legal, ethical, and financial consequences in addition to medical repercussions, is the most important aspect of ensuring patient safety. Operating room nurses have a significant role in ensuring and maintaining patient safety $(9,11)$. Determining the workload perceptions of nurses and 
their tendencies toward malpractice will help to identify the sources of malpractice in the operating room and to create more efficient working conditions for both the patient and the employee. In this way, approaches to be developed to foresee and prevent malpractice in operating rooms may ensure a safe perioperative process.

This study was performed to determine the workload perceptions and malpractice tendencies of nurses working in operating rooms.

\section{METHODS}

This was a descriptive and cross-sectional study. Three hospitals located in three different regions of Turkey were included. The inclusion criteria was: to be working in the operating room for at least a year. A total of 118 operating room nurses were working at these hospitals. The goal was to reach all of the nurses; however, due to various reasons (sick leaves, on leave status, refusal to participate), the study ultimately involved 92 nurses. To conduct this study, permission was obtained from the local ethics committee (Mehmet Akif Ersoy University Non-Invasive Clinical Researches Assessment Commission-GO 2017/96) and the institution, and written and verbal consent was obtained from the nurses who accepted participating in the research.

\subsection{Measurements}

Data collection tools were a Personal Data Form, the Individual Workload Perception Scale (IWPS), and the Malpractice Tendency Scale (MTS). The Individual Data Form, developed by the investigators on the basis of the relevant literature, $(9$, 12,13 ) included 12 questions on descriptive features (age, sex, education status, working time in the nursing profession, working time in an operating room, weekly workload, and previous encounters with malpractice).

Individual Workload Perception Scale: Cox (2007). developed the Individual Workload Perception Scale (14). The validity and reliability study of the Turkish version of the Revised Individual Workload Scale was performed by Ozyurek \& Kilic (2017). The Cronbach alpha coefficient of the scale was found to be 0.923. This Likert-type 5-point scale consists of 29 items and is scored as "1=none", "2=minimal", " $3=$ moderate", "4=very", and " $5=$ full". The scale consists of five subscales. Peer support comprises items 1-6, unit support comprises items 7-12, manager support corresponds to items 13-20, workload to items 21-24, and intention to stay at work comprises items 2529. The mean score from each of the IWPS items is minimum 1 and maximum 5. A higher total score reflects a positive workload perception and general nurse satisfaction (15). In our study, the Cronbach alpha coefficient was 0.735 .

Malpractice Tendency Scale: Ozata \& Altunkan (2010) developed the Malpractice Tendency Scale to measure the malpractice tendency of health care personnel (nurse, midwife, paramedic) directly caring for patients and tested its validity and reliability (16). This scale's 5 subscales consist of drug and transfusion practices (18 items), prevention of infections (12 items), prevention of falls (5 items), patient monitoring and material safety ( 9 items) and communication (5 items). There are 49 items included in the scale, and a 5 -point Likert type rating is used to respond to the items as "1-never, 2-very rarely, 3-sometimes, 4-usually, and 5 -always". The lowest possible score was 49, and the highest possible score was 245 . A higher score from the scale reflects a low malpractice tendency, and a lower score reflects a high malpractice tendency for nurses (17). The Cronbach alpha coefficient of the scale was found to be 0.95 (16). In our study, the Cronbach alpha coefficient was found to be 0.88 .

\subsection{Data Collection and Analysis}

The study data were collected with face-to-face interviews between June 2017 and January 2018. The time for filling the data collection forms is about 10-15 minutes. The data were analyzed using the Statistical Package for Social Sciences (SPSS) 23. The Shapiro-Wilk tests were used to determine whether the data obtained were normally distributed. Numbers, percentages, the Mann-Whitney $U$ test and the Kruskal Wallis test were used to evaluate the data. The level of significance was set at $\leq 0.05$ for all the tests performed.

\section{RESULTS}

The mean age of the nurses who participated in this study was $35.19 \pm 6.11$ years, and $80.4 \%(n=74)$ were females. A total of $50 \%(n=46)$ of the participants were faculty graduates, $65.2 \%$ $(n=60)$ had been working for a period of 11 years or more, $50 \%$ had worked in an operating room for a period of 1-5 years, and $78.3 \%(n=72)$ worked for more than 40 hours a week; $33.7 \%$ of the nurses $(n=31)$ previously encountered a malpractice case.

The mean Malpractice Tendency Scale score of the participants was $225.59 \pm 12.75$, and the mean Individual Workload Perception Scale score was 98.82 \pm 9.39 . The minimum, maximum and mean values of the subscales of the two scales are given in Table 1.

Table 1. The Distribution of the Mean Scores from the Malpractice Tendency Scale and Individual Workload Perception Scale of the Operating Room Nurses $(\mathrm{N}=92)$

\begin{tabular}{|c|c|c|c|}
\hline & Min. & Max. & $(X \pm S D)$ \\
\hline Malpractice Tendency & 191 & 243 & $225.59 \pm 12.75$ \\
\hline Drug and Transfusion Applications & 76 & 90 & $85.80 \pm 3.66$ \\
\hline Prevention of Infections & 45 & 60 & $53.86 \pm 3.76$ \\
\hline Prevention of Falls & 15 & 25 & $21.65 \pm 2.39$ \\
\hline $\begin{array}{l}\text { Patient Monitoring and Material } \\
\text { Safety }\end{array}$ & 30 & 45 & $38.60 \pm 3.65$ \\
\hline Communication & 15 & 25 & $22.80 \pm 2.81$ \\
\hline Individual Workload Perception & 75 & 116 & $98.82 \pm 9.39$ \\
\hline Manager Support & 9 & 30 & $22.45 \pm 5.29$ \\
\hline Peer Support & 8 & 29 & $22.10 \pm 2.76$ \\
\hline Unit Support & 24 & 30 & $26.65 \pm 1.20$ \\
\hline Intention to Stay at Work & 4 & 17 & $15.58 \pm 1.81$ \\
\hline Workload & 8 & 19 & $12.02 \pm 2.85$ \\
\hline
\end{tabular}


No significant differences could be found between the mean total and subscale scores of the nurses who participated in the study and the variables of gender, weekly working hours, and encounters with malpractice $(p>0.05)$. There was a significant difference in the communication subscale mean score on the Malpractice Tendency Scale of the nurses according to educational status $(p<0.05)$. The communication subscale mean score of high school graduates was higher. There was a statistically significant difference between the communication subscale mean scores of the participants on the Malpractice Tendency Scale according to their time in the profession $(p<0.05)$. Those who worked for 11 years or more in the profession had higher mean scores in the communication subscale (Table 2).

Table 2. Comparison of the mean malpractice tendency scores for several independent variables ( $N=92)$

\begin{tabular}{|c|c|c|c|c|c|c|}
\hline Variable & $\begin{array}{l}\text { Drug and } \\
\text { Transfusion } \\
\text { Practices }\end{array}$ & $\begin{array}{l}\text { Prevention of } \\
\text { Infections }\end{array}$ & $\begin{array}{c}\text { Prevention of } \\
\text { Falls }\end{array}$ & $\begin{array}{c}\text { Patient Monitoring } \\
\text { and Material } \\
\text { Safety }\end{array}$ & Communication & $\begin{array}{c}\text { Malpractice Trend } \\
\text { Total }\end{array}$ \\
\hline $\begin{array}{l}\text { Gender } \\
\text { Female } \\
\text { Male } \\
p^{*} \\
\text { U** }^{*}\end{array}$ & $\begin{array}{c}85.81 \pm 3.71 \\
85.77 \pm 3.57 \\
0.90 \\
654.00\end{array}$ & $\begin{array}{c}53.72 \pm 3.72 \\
54.44 \pm 3.98 \\
0.40 \\
582.50\end{array}$ & $\begin{array}{c}21.51 \pm 2.22 \\
22.22 \pm 3.00 \\
0.14 \\
518.50\end{array}$ & $\begin{array}{c}38.72 \pm 3.57 \\
38.11 \pm 4.05 \\
0.42 \\
586.00\end{array}$ & $\begin{array}{c}22.75 \pm 2.85 \\
23.00 \pm 2.74 \\
0.64 \\
621.00\end{array}$ & $\begin{array}{c}222.54 \pm 10.76 \\
223.55 \pm 13.91 \\
0.42 \\
584.50\end{array}$ \\
\hline $\begin{array}{l}\text { Education } \\
\text { High School } \\
\text { Faculty } \\
\text { p* }^{*} \\
\mathrm{U}^{* *}\end{array}$ & $\begin{array}{c}86.39 \pm 3.05 \\
85.21 \pm 4.14 \\
0.26 \\
915.50\end{array}$ & $\begin{array}{c}54.06 \pm 3.65 \\
53.67 \pm 3.91 \\
0.70 \\
1010.00\end{array}$ & $\begin{array}{c}21.58 \pm 2.58 \\
21.71 \pm 2.21 \\
0.90 \\
1042.50\end{array}$ & $\begin{array}{c}38.10 \pm 4.19 \\
39.10 \pm 2.99 \\
0.30 \\
928.50\end{array}$ & $\begin{array}{c}23.58 \pm 2.15 \\
22.02 \pm 3.18 \\
0.005 \\
717.50\end{array}$ & $\begin{array}{c}223.73 \pm 11.07 \\
221.73 \pm 11.69 \\
0.34 \\
938.00\end{array}$ \\
\hline $\begin{array}{l}\text { Working time in the } \\
\text { profession } \\
1-5 \text { years } \\
6-10 \text { years } \\
11 \text { years and above } \\
\text { p } \\
\mathrm{KW}^{* * *}\end{array}$ & $\begin{array}{c}85.68 \pm 3.66 \\
85.43 \pm 4.21 \\
85.93 \pm 3.56 \\
0.97 \\
0.05\end{array}$ & $\begin{array}{c}53.93 \pm 4.15 \\
54.12 \pm 2.65 \\
53.78 \pm 3.96 \\
0.99 \\
0.02\end{array}$ & $\begin{array}{c}20.56 \pm 2.30 \\
22.31 \pm 1.77 \\
21.76 \pm 2.49 \\
0.08 \\
4.86\end{array}$ & $\begin{array}{c}38.37 \pm 3.15 \\
38.37 \pm 2.65 \\
38.73 \pm 4.03 \\
0.86 \\
0.28\end{array}$ & $\begin{array}{c}20.81 \pm 4.26 \\
22.12 \pm 2.41 \\
23.51 \pm 2.10 \\
0.007 \\
9.87\end{array}$ & $\begin{array}{c}219.37 \pm 10.37 \\
222.37 \pm 10.90 \\
223.73 \pm 11.73 \\
0.18 \\
3.39\end{array}$ \\
\hline $\begin{array}{l}\text { Working time in } \\
\text { operating room } \\
1-5 \text { years } \\
6-10 \text { years } \\
11 \text { years and above } \\
\text { p } \\
\mathrm{KW}^{* * *}\end{array}$ & $\begin{array}{c}86.58 \pm 3.33 \\
85.40 \pm 3.77 \\
84.83 \pm 3.92 \\
0.89 \\
4.84\end{array}$ & $\begin{array}{c}54.06 \pm 3.51 \\
53.93 \pm 3.30 \\
53.54 \pm 4.38 \\
0.92 \\
0.15\end{array}$ & $\begin{array}{c}21.76 \pm 2.46 \\
21.86 \pm 2.03 \\
21.38 \pm 2.49 \\
0.65 \\
0.84\end{array}$ & $\begin{array}{c}39.06 \pm 3.44 \\
38.60 \pm 3.73 \\
37.93 \pm 3.93 \\
0.58 \\
1.07\end{array}$ & $\begin{array}{c}22.36 \pm 3.22 \\
23.40 \pm 2.26 \\
23.16 \pm 2.35 \\
0.40 \\
1.81\end{array}$ & $\begin{array}{c}223.84 \pm 10.40 \\
223.20 \pm 10.94 \\
220.87 \pm 12.96 \\
0.80 \\
0.44\end{array}$ \\
\hline $\begin{array}{l}\text { Weekly working hours } \\
40 \text { hours or lower } \\
\text { Above } 40 \text { hours } \\
p^{*} \\
\text { U** }^{*}\end{array}$ & $\begin{array}{c}84.85 \pm 5.12 \\
86.06 \pm 3.14 \\
0.72 \\
683.00\end{array}$ & $\begin{array}{c}52.50 \pm 4.62 \\
54.25 \pm 3.43 \\
0.13 \\
563.50\end{array}$ & $\begin{array}{c}22.50 \pm 2.50 \\
21.41 \pm 2.33 \\
0.08 \\
541.00\end{array}$ & $\begin{array}{c}39.20 \pm 4.39 \\
38.44 \pm 3.44 \\
0.40 \\
632.50\end{array}$ & $\begin{array}{c}22.65 \pm 2.83 \\
22.84 \pm 2.83 \\
0.86 \\
703.00\end{array}$ & $\begin{array}{c}221.00 \pm 17.39 \\
223.02 \pm 9.18 \\
0.77 \\
689.50\end{array}$ \\
\hline $\begin{array}{l}\text { Malpractice encounters } \\
\text { None } \\
\text { Once or more } \\
p^{*} \\
U^{* *}\end{array}$ & $\begin{array}{c}85.98 \pm 3.58 \\
85.45 \pm 3.84 \\
0.43 \\
852.50\end{array}$ & $\begin{array}{c}53.96 \pm 3.51 \\
53.67 \pm 4.28 \\
0.95 \\
938.50\end{array}$ & $\begin{array}{c}21.49 \pm 2.39 \\
21.96 \pm 2.41 \\
0.44 \\
853.50\end{array}$ & $\begin{array}{c}38.90 \pm 3.52 \\
38.03 \pm 3.90 \\
0.30 \\
822.00\end{array}$ & $\begin{array}{c}22.49 \pm 2.99 \\
23.41 \pm 2.36 \\
0.11 \\
765.00\end{array}$ & $\begin{array}{c}222.83 \pm 10.70 \\
222.54 \pm 12.76 \\
0.58 \\
879.00\end{array}$ \\
\hline
\end{tabular}

No statistically significant difference could be found between the overall and subscale mean scores on the Individual Workload Perception Scale and education status or malpractice encounters $(p>0.05)$. There were statistically significant differences between the gender of the participants and the overall Individual Workload Perception Scale mean score, the managerial support subscale mean score, and the workload subscale score $(p<0.05)$. Female participants were found to have higher levels of individual workload performance. Statistically significant differences were detected between the working time of the nurses and the managerial support subscale and the workload subscale scores $(p<0.05)$. Nurses who worked for five years or less in the profession were detected to have a lower level of individual workload perception. Significant differences were detected in the participants' mean scores on the intention to stay at work subscale of the Individual Workload Performance Scale according to the operating room working time of the participants $(p<0.05)$. Nurses who worked for 11 years or more were less eager to stay in their current jobs. There was a statistically significant difference in the Workload Subscale of the individual workload perception scale according to the weekly working hours of the nurses $(p<0.05)$. Employees whose weekly working hours were 40 hours or more had higher workload perceptions (Table 3). 
Table 3. The Comparison of the mean individual workload scale scores according to independent variables ( $\mathrm{N}=92$ )

\begin{tabular}{|c|c|c|c|c|c|c|}
\hline Variables & $\begin{array}{l}\text { Manager } \\
\text { Support }\end{array}$ & Peer Support & Unit Support & $\begin{array}{c}\text { Intention to Stay } \\
\text { at Work }\end{array}$ & Workload & $\begin{array}{c}\text { Individual Workload } \\
\text { Total }\end{array}$ \\
\hline $\begin{array}{l}\text { Gender } \\
\text { Female } \\
\text { Male } \\
\mathrm{p}^{*} \\
\mathrm{U}^{* *}\end{array}$ & $\begin{array}{c}21.50 \pm 5.29 \\
26.38 \pm 3.01 \\
0.001 \\
297.50\end{array}$ & $\begin{array}{c}22.02 \pm 2.78 \\
22.44 \pm 2.74 \\
0.33 \\
571.00\end{array}$ & $\begin{array}{c}26.64 \pm 1.17 \\
26.66 \pm 1.37 \\
0.74 \\
634.50\end{array}$ & $\begin{array}{c}15.48 \pm 1.92 \\
16.00 \pm 1.23 \\
0.43 \\
589.00\end{array}$ & $\begin{array}{c}11.67 \pm 2.91 \\
13.44 \pm 2.12 \\
0.01 \\
428.50\end{array}$ & $\begin{array}{c}97.33 \pm 9.37 \\
104.94 \pm 6.79 \\
0.001 \\
325.50\end{array}$ \\
\hline $\begin{array}{l}\text { Education } \\
\text { High School } \\
\text { Faculty } \\
\text { p* } \\
\mathrm{U}^{* *}\end{array}$ & $\begin{array}{c}21.89 \pm 5.12 \\
23.02 \pm 5.44 \\
0.21 \\
898.00\end{array}$ & $\begin{array}{c}21.78 \pm 3.18 \\
22.43 \pm 2.26 \\
0.59 \\
991.50\end{array}$ & $\begin{array}{c}26.47 \pm 1.24 \\
26.82 \pm 1.16 \\
0.07 \\
839.50\end{array}$ & $\begin{array}{c}15.47 \pm 2.21 \\
15.69 \pm 1.31 \\
0.97 \\
1054.00\end{array}$ & $\begin{array}{c}11.58 \pm 2.67 \\
12.45 \pm 2.99 \\
0.08 \\
836.50\end{array}$ & $\begin{array}{c}97.21 \pm 10.00 \\
100.43 \pm 8.55 \\
0.06 \\
819.00\end{array}$ \\
\hline $\begin{array}{l}\text { Working time } \\
1-5 \text { years } \\
6-10 \text { years } \\
11 \text { years and above } \\
\mathrm{p}^{*} \\
\mathrm{KW} * * *\end{array}$ & $\begin{array}{l}25.31 \pm 3.85 \\
20.12 \pm 5.80 \\
22.31 \pm 5.20 \\
0.01 \\
8.09\end{array}$ & $\begin{array}{l}22.06 \pm 2.26 \\
22.12 \pm 4.39 \\
22.11 \pm 2.36 \\
0.94 \\
0.12\end{array}$ & $\begin{array}{c}26.75 \pm 1.12 \\
26.93 \pm 1.06 \\
26.55 \pm 1.26 \\
0.55 \\
1.16\end{array}$ & $\begin{array}{c}15.81 \pm 0.75 \\
15.81 \pm 1.22 \\
15.46 \pm 2.12 \\
0.99 \\
0.01\end{array}$ & $\begin{array}{c}13.43 \pm 1.78 \\
10.43 \pm 3.05 \\
12.06 \pm 2.85 \\
0.01 \\
8.97\end{array}$ & $\begin{array}{c}103.37 \pm 5.87 \\
95.43 \pm 11.24 \\
98.51 \pm 9.29 \\
0.06 \\
5,60\end{array}$ \\
\hline $\begin{array}{l}\text { Operating room working time } \\
1-5 \text { years } \\
6-10 \text { years } \\
11 \text { years and above } \\
\mathrm{p}^{*} \\
\mathrm{KW} * * *\end{array}$ & $\begin{array}{c}21.89 \pm 5.73 \\
24.33 \pm 4.22 \\
22.38 \pm 4.99 \\
0.35 \\
2.07\end{array}$ & $\begin{array}{c}21.69 \pm 2.76 \\
22.13 \pm 3,09 \\
22.70 \pm 2.58 \\
0.54 \\
1.20\end{array}$ & $\begin{array}{c}26.54 \pm 1.14 \\
27.13 \pm 0.99 \\
26.58 \pm 1.36 \\
0.25 \\
2.69\end{array}$ & $\begin{array}{c}15.50 \pm 1.22 \\
15.33 \pm 2.16 \\
15.83 \pm 2.33 \\
0.03 \\
6.48\end{array}$ & $\begin{array}{c}11.67 \pm 2.51 \\
11.66 \pm 2.58 \\
12.70 \pm 3.37 \\
0.08 \\
4.84\end{array}$ & $\begin{array}{c}97.30 \pm 8.82 \\
100.60 \pm 9.13 \\
100.22 \pm 10.24 \\
0.20 \\
3.16\end{array}$ \\
\hline $\begin{array}{l}\text { Weekly working hours } \\
40 \text { hours and below } \\
\text { Above } 40 \text { hours } \\
\text { p* }^{*} \\
U^{* *}\end{array}$ & $\begin{array}{c}24.15 \pm 4.77 \\
21.98 \pm 5.36 \\
0.07 \\
531.50\end{array}$ & $\begin{array}{c}21.95 \pm 1.31 \\
22.15 \pm 3.05 \\
0.44 \\
642.50\end{array}$ & $\begin{array}{c}26.75 \pm 0.71 \\
26.62 \pm 1.31 \\
0.68 \\
678.50\end{array}$ & $\begin{array}{c}15.15 \pm 1.59 \\
15.70 \pm 1.86 \\
0.07 \\
536.50\end{array}$ & $\begin{array}{c}13.55 \pm 2.16 \\
11.59 \pm 2.89 \\
0.01 \\
453.00\end{array}$ & $\begin{array}{c}101.55 \pm 7.45 \\
98.06 \pm 9.77 \\
0.16 \\
573.50\end{array}$ \\
\hline $\begin{array}{l}\text { Malpractice encounters } \\
\text { Once or more } \\
\text { None } \\
p^{*} \\
U^{* *}\end{array}$ & $\begin{array}{c}22.27 \pm 5.21 \\
22.80 \pm 5.50 \\
0.57 \\
877.50\end{array}$ & $\begin{array}{c}21.75 \pm 2.83 \\
22.80 \pm 2.53 \\
0.45 \\
858.50\end{array}$ & $\begin{array}{c}26.60 \pm 1.25 \\
26.74 \pm 1.12 \\
0.55 \\
877.00\end{array}$ & $\begin{array}{c}15.36 \pm 2.12 \\
16.03 \pm 0.83 \\
0.14 \\
774.00\end{array}$ & $\begin{array}{c}11.91 \pm 2.72 \\
12.22 \pm 3.13 \\
0.46 \\
858.50\end{array}$ & $\begin{array}{c}97.91 \pm 9.27 \\
100.61 \pm 9.52 \\
0.21 \\
797.00\end{array}$ \\
\hline
\end{tabular}

* $p:(p<0.05) ;{ }^{* *}$ : The Mann-Whitney U Test; ${ }^{* * *} K W:$ The Kruskal-Wallis Test

\section{DISCUSSION}

In our study, the Malpractice Tendency Scale mean score of the nurses was $225.59 \pm 12.75$. Because the highest possible score in the Malpractice Tendency Scale is 245 , it can be said that the tendency of the participating nurses toward malpractice was low. Similar to our study, malpractice tendencies in nurses were low in other studies $(12,13,17)$. This may be due to the continuous in-service training nurses receive and the success of the protocols developed by the Ministry of Health in the effort to prevent malpractice in accordance with quality standards. In our study, the dimensions in which operating room nurses were more likely to lean toward malpractice included patient monitorization and materials safety, fall prevention, and the prevention of infections. The dimension of patient monitorization and materials safety reflects malpractice tendencies in the auditing of all equipment and materials and in monitoring patients. The highest possible score on this scale is 45 ; the nurses in our study scored 38.60 points. The highest possible score in the fall prevention subscale is 25 ; the mean score of the nurses in our study was 21.65 . The infection subscale reflects malpractice tendencies regarding the use of aseptic techniques in the care of patients and in nursing practices. The nurses in this study displayed a mean score of 53 while the highest possible score is 60 . In another study, nurses displayed the highest mean subscale scores on the prevention of infection and communication subscales and the lowest mean scores on the patient monitorization and the material and equipment safety subscales (18). The shortage of nurses working in operating rooms leads to obliging scrub nurses to additionally perform the duties of circulating nurses during surgeries. This causes an increased tendency toward malpractice in the domain of patient and materials safety. Although the scores in our study were not very low, the desired outcome in terms of decreasing the number of infections and falls was to obtain the highest mean scores in this dimension. In particular, the responsibilities of nurses 
increase in all the aspects of patient safety when a patient inevitably lies unconscious under anesthesia in the operating room. Studies show that most nurses have encountered cases of medical error $(18,19,20)$. In our study, only $33.7 \%$ of the nurses had not encountered a case of medical error. According to the Safety Reporting System Statistics and Analysis Report of the Ministry of Health, 74,383 cases of malpractice were reported in 2016 (21). Also, among all professional groups, nurses were the group making the most frequent errors. The reasons cited for this have been the fact that nurses constitute the majority of healthcare professionals, they take active roles in all healthcare procedures, and their level of awareness for error reporting is high (17). In our study, the mean score of the operating room nurses who were high school graduates was higher on the communication subscale of the Malpractice Tendency Scale. The communication subscale evaluates communications with peers and other disciplines. It is emphasized that the leading cause of cases of malpractice in operating rooms is a lack of communication $(18,22)$. Among the participants, those who had worked for 11 years or more had higher mean scores on the communication subscale. This indicates that communication skills improve as the number of working years increase and also means that malpractice due to lack of communication is preventable. Ugur, et al. (2011) included all healthcare workers in the operating room in their study and reported that $37.7 \%$ of malpractice cases were due to mistakes in communication and data flow. Studies have shown that tendencies toward malpractice diminished as the number of working years increased. Our study is in parallel with these findings $(13,23)$. The overall mean score on the Individual Workload Perception Scale was $98.82 \pm 9.39$. While the highest possible score in the scale is 145 , the score found in the study indicated that workload perceptions of the nurses were at a moderate level, meaning that the level of satisfaction was not very high. Among the subscales of the Individual Workload Perception scale, the mean Unit Support subscale score was higher than in the other dimensions. The Unit Support subscale reflects the satisfaction of employees regarding the provision of required materials and service support. This result suggests that using the appropriate materials may be effective in reducing the number of malpractice cases. It is also reported in the literature that technical factors (insufficient automation, insufficient or defective devices, lack of support and integration) are among the causes of malpractice (21). The intention to stay at work subscale is the combination of the other dimensions and reflects the intention of employees to stay at their current jobs for the next year. It was determined in our study that the intention to stay at work subscale mean scores of the nurses who had worked 11 years or more were higher. Higher mean scores indicate a higher level of intent to stay in the current job. This result may be due to the fact that experienced operating room nurses occupy positions of competence that require higher levels of responsibility and therefore they are more likely to take more satisfaction out of their jobs. In another study that investigated the individual workload perceptions of healthcare employees, it was reported that the employees received the lowest scores from the intention to stay at work dimension (24). In addition, the more the number of years' nurses worked, the more there was an increase in their professional satisfaction and professional quality of life. On the other hand, it was seen that the mean scores on the managerial support, peer support and direct workload subscales were lower, pointing to more negative perceptions. Managerial support is essential in operating room nursing, and it is especially important for inexperienced nurses. Operating rooms are open to conflict due to the complexities of having multiple disciplines work together and the necessity for highly technical skills $(25,26)$. Under these circumstances, enlisting the support of nurse supervisors is important for establishing and maintaining a well-working team and preventing incidents of malpractice $(27,28)$. In the study conducted by Ciftcioglu et al. (2018), the highest results were in the peer support, managerial support, and workload subscales (24). Similar studies have also demonstrated that the highest subscale scores appear on the peer support subscale (14). Another study found that the highest scoring subscale of the Individual Workload Perception Scale was the managerial support subscale (23). The direct workload subscale reflects the effect of the workload on employees and is affected by factors such as expectations, resource sufficiency, sufficient number of competent personnel, and fair distribution of duties (14). All of these factors are necessary for the effective conduct of healthcare services (2). Many factors may be responsible for the fact that the mean workload subscale score was lower than in the other subscales in our study. One of these is the long working hours. In our study, the direct workload perception scores of the group that was working 40 hours or more were higher. In another study, it was reported that it was the higher number of night shifts nurses worked that was the cause of the increase in the perceptions of workload in the direct workload subscale (23). According to the regulations of the International Labor Organization (ILO) on the working hours of healthcare workers, the recommendation is a 40 -hour working week for nurses $(29,30)$. Although the number of hours is officially defined by law, nurses usually work more than what has been stipulated. Working shifts and long working hours are reported to cause stress, fatigue, diminished performance and professional satisfaction, and higher workload perceptions, all of which increases the risk of malpractice $(7,16)$. Also in our study, there was a significant difference found between the workload subscale and years spent in the profession; satisfaction was higher in nurses who had been working for 5 years or less. This was found to be due to the support supervisors offer young nurses starting to work in the operating rooms. This hypothesis is also supported by the fact that the managerial support subscale mean score was the highest in this young age group. There were significant differences in terms of the gender variable in the managerial support, direct workload, and the overall Individual Workload Perception Scale; it was determined that male participants had higher mean scores. Ozyer, (2016) also found higher scores in the peer support subscale in male nurses (23). Ciftcioglu, et al. (2018) could not detect any 
differences in the overall and subscale scores of the Individual Workload Performance Scale according to the gender variable (24). We think that the difference in our study was due to the fewer number of male participants in our study.

\section{CONCLUSION}

In conclusion, we found that operating room nurses perceived their workloads to be at high levels. This perception was related to many factors such as long working hours, communication, materials support, and support from peers and managers. Trying to improve the working conditions of nurses working in operating rooms in which malpractice can causes grave consequences is a priority if possible cases of malpractice are to be prevented. In addition, effective communication within the team should be established to achieve safety in healthcare in the operating room, and all operating room team members should develop and adopt an institutional culture of patient safety. In particular, support offered to new nurses in the operating room by their seniors, improving technical and environmental conditions, and upto-date in-service training may be recommended to develop the culture of patient safety in the institution and to reduce malpractice in the operating rooms.

\section{Acknowledgements}

The manuscript presented as oral at 2nd International \& 10th National Congress of Turkish Surgical and Operating Room Nurses between 2 - 5 November 2017 in Antalya, Turkey. We did not have financial support for this research.

Decleration of Interest Statement: The authors have no conflicts of interest to declare. This research received no specific grant from any funding agency in the public, commercial, or not-for-profit sectors.

Funding: This research received no specific grant from any funding agency in the public, commercial, or not-for-profit sectors

\section{REFERENCES}

[1] Akansel N. International and National Patient Safety. Yavuz van Giesbergen M, Kaymakçı Ş. editors. Operating Room Nursing. İzmir: Meta Edition, 2015.

[2] Balanuye B. The effects of workloads of nurses whom work in surgical clinics on patient safety. Baskent University Health Science Institute, Master Thesis. 2014. (Turkish)

[3] Sayed HA, Zayed M, El Qareh NM, Khafagya H, Helmya $\mathrm{AH}$, Soliman M. Patient safety in the operating room at a governmental hospital. J Egypt Public Health Assoc 2013; 88: 85-89.

[4] Joint Commission on Accreditation of Healthcare Organizations (JCAHO); Sentinel Event Statistics 2011 [January 2019]. Available from: http://www.jointcomission.org/assests/1/18/ general_Information_1195-3Q2011.pdf.
[5] Rubin JD, Janovic EV, Gulinello C. \$20 million award to parents for removal of the wrong side of child's brain. Healthcare Risk Management AVR.2013;3-4.

[6] Taşdemir N. Wrong person, region, procedure. Yavuz van Giesbergen M, Kaymakçı Ş, editors. Operating Room Nursing. İzmir, Meta Edition, 2015.

[7] Akın Korhan E, Dilemek H, Mercan S, Uzelli Yilmaz D. Determination of attitudes of nurses in medical errors and related factors. International Journal of Caring Sciences 2017; 10(2):794-801.

[8] Makary MA, Daniel M. Medical error - the third leading cause of death in the US. BMJ 2016; 353:i2139:1-5. doi:10.1136/bmj.i2139.

[9] Işık O, Akbolat M, Çetin M, Çimen M. The causes of medical error from the perspective of nurses. TAF Prev Med Bull 2012;11(4):421-430.

[10] Şahin ZA, Özdemir FK. Examination of the tendency for nursing malpractice and affecting factors. Hemşirelikte Araştırma ve Geliştirme Dergisi 2015; 12(3):210-214. (Turkish)

[11] Uğur E, Kara S, Yıldırım S, Akbal E. Errors that threaten patient safety in the operating room and the attitude of the health personnel. Turkish Journal of Neurosurgery 2011;21: 279. (Turkish)

[12] Cebeci F, Gürsoy E, Tekin Gündüz S. Determining the level of tendency in malpractice among nurses. Anadolu Hemşirelik ve Sağlık Bilimleri Dergisi 2012; 15(3):188-196. (Turkish)

[13] Dikmen DY, Yorgun S, Yeşilçam N. Identification the level of tendency in malpractice among nurses. Journal of Hacettepe University Faculty of Nursing 2014; 32(1):44-56.

[14] Cox KS, Teasley SL, Lacey SR, Sexton K, Carroll CA. Work environment perceptions of pediatric nurses. Journal of Pediatric Nursing 2007; 22(1):179-182.

[15] Ozyurek P, Kilic I. Validity and reliability study of Turkish form of the revised individual workload perception scale, 8th. congress EORNA Colossus of perioperative nursing. Abstract Book. Greece, 4-7 May, 2017; EPO37. 201-211.

[16] Özata M, Altunkan H. Frequency of medical errors in hospitals, determination of medical error types and medical errors: Konya sample. Tıp Araştırmaları Dergisi 2010;8(2):100-11.(in Turkish)

[17] Güleç D, İntepeler SŞ. Developing a scale of attitudes towards medical errors. Hemşirelikte Araştırma ve Geliştirme Dergisi 2013; 15(3):26-41. (Turkish)

[18] Işık Andsoy I, Kar G, Öztürk Ö. A Study on trends to medical error for nurses. Journal of Health Science and Profession 2014; 1(1):17-27.

[19] Güneş ÜY, Gürlek Ö, Sönmez M. Factors contributing to medication errors in Turkey: nurses' perspectives. Journal of Nursing Management 2014; 22:295-303.

[20] Mrayyan MT, Shishani K, Al-Faouri I. Rate, causes and reporting of medication errors in Jordan: Nurses' perspectives. Journal of Nursing Management 2007; 15: 659-670.

[21] Ministry of Health, Security Reporting System Statistics and Analysis Report 2016 [January 2019]. Available from: https:// grs.saglik.gov.tr/BM/Reports/GRS2016Rapor_R1.pdf.

[22] Cvetic E. Communication in the perioperative setting. AORN J 2011; 94:261-270.

[23] Özyer Y. Workload Perception, work-related stress and medical error attitudes of nurses working in surgical clinics. Masters Program with Nursery Thesis. Ordu University Health Science Institute, 2016. (Turkish) 
[24] Çiftçioğlu G, Tunç G, Güneş A, Değer V, Çiftçi S. Indiviual workload perceptions of health workers employed in hospitals. Journal of Health and Nursing Managament 2018; 1(5):1-9.

[25] Aksoy N, Polat C. Job Satisfaction and affecting factors of surgical unit nurses of three different hospitals in a province in mediterranean region. Koç Üniversitesi Hemşirelikte Eğitim ve Araştırma Dergisi 2013; 10(2):45-53. (Turkish).

[26] Tan M, Polat $H$, Şahin ZA. Assessing perception of nurses regarding work environments. Journal of Performance and Quality in Health 2012;4:67-78.

[27] Beverly A. Kirchner dealing with disruptive behavior in the perioperative setting. In: Watson DS, editor. Perioperative Safety. St Louis, MO: Mosby Elsevier; 2011.
[28] McNamara SA. Preventive measures for wrong-site, wrongperson, and wrong-procedure error in the perioperative setting. In: Watson DS, editor. Perioperative Safety. St Louis, MO: Mosby Elsevier; 2011.

[29] Ministry of Health Circular of Health Employees Working Hours 2010 [January 2019]. Available from: https:// www.saglik.gov.tr/TR,11025/saglik-personeli-calismasaatleri-201055.html.

[30] Nursing Personnel Convetion. In Employment and Conditions of Work and Life of Nursing Personnel, 63rd ILC session. Geneva: International Labour Organization (ILO), 1977 [January 10, 2019]. Available from: URL: http://www.ilo.org/ dyn/normlex/en/f?p=NORMLE

How to cite this article: Savci A, Karacabay K, Comez S, Karaveli S, Celik N. Determining Individual Workload Perceptions and Malpractice Tendencies Among Operating Room Nurses. Clin Exp Health Sci 2020; 10: 348-354. DOI: 10.33808/ clinexphealthsci.628440 